\title{
Modeling Performance of High-Temperature Biomass Gasification Process
}

\author{
C. F. Mhilu \\ College of Engineering and Technology, University of Dar es Salaam, P.O. Box 35131, Dar es Salaam, Tanzania \\ Correspondence should be addressed to C. F. Mhilu, cfmhilu@hotmail.com
}

Received 20 July 2012; Accepted 10 August 2012

Academic Editors: J. Canosa and A. M. Seayad

Copyright ( 2012 C. F. Mhilu. This is an open access article distributed under the Creative Commons Attribution License, which permits unrestricted use, distribution, and reproduction in any medium, provided the original work is properly cited.

Biomass utilization is becoming a subject of increasing interest as an alternative to clean fuel. A novel gasification process using highly preheated air gasifier using agricultural residue such as sugar bagasse, rice husks, and palm stem widely available in Tanzania is presented. The study examines, irreversibilities making the gasifier the least efficient unit in the gasification process employing a thermodynamic equilibrium model allowing predicting the main product gas composition $\mathrm{CO}, \mathrm{CO}_{2}, \mathrm{H}_{2}$, and $\mathrm{CH}_{4}$. The derived model equations are computed using the MAPLE process simulation code in MATLAB. The gasification regime is investigated at temperatures ranging from $800 \mathrm{~K}$ to $1400 \mathrm{~K}$ and at equivalence ratio (ER) values between 0.3 and 0.4 . The results obtained conform to the second law efficiency based on chemical exergy yielding maximum values for the types of biomass materials used. These results indicate that the application of preheated air has an effect on the increase of the chemical exergy efficiency of the product gas, hence reducing the level of irreversibility. Similarly, these results show that the combined efficiency based on physical and chemical exergy is low, suggesting that higher irreversibilities are encountered, since the exergy present in the form of physical exergy is utilized to heat the reactants. Such exergy losses can be minimized by altering the ratio of physical and chemical exergy in the syngas production.

\section{Introduction}

The need for sustainable energy sources is growing as fossil energy sources are diminishing. Moreover, stringent environmental laws about the greenhouse gas emissions and increase in oil prices are prompting for the need to invest in the area of renewable energy sources. Biomass referring to all the forms of plant-based material that can be converted into usable energy is a renewable source of energy.

In Tanzania, biomass is in abundance and is a nonconventional source of energy. The main biomass sources available are in the form of wood sawdust and agricultural residues. The utilization of biomass in an efficient and sustainable manner will provide sufficient energy which can be utilized for electricity generation, engine applications, and so forth, through the deployment of gasification technology. Gasification is the process in which biomass is converted into clean and combustible gas in the presence of limited amount of air.

Thermoconversion process of biomass based on the gasification technology is the most convenient way for the utilization of biomass and is believed to be an efficient method for converting biomass materials into a useful energy source compared to other conversion processes. When compared to conventional combustion technologies, biomass gasification can offer a greater reduction potential on the formation of $\mathrm{CO}_{2}$ and $\mathrm{NO}_{x}$ compounds. The composition of each component varies due to specific gasifier conditions. Use of low temperature in the gasification process below $750^{\circ} \mathrm{C}$ is known to be associated with a high formation of tars that remain in the syngas and do not crack into more volatile components. The presence of tars in syngas renders it unsuitable for most engines and gas turbines applications. The other main problem associated with lowtemperature gasification is the low-calorific value of the gas of about $3-5 \mathrm{MJ} / \mathrm{kg}$. The poor performance of lowtemperature gasification processes can partly be overcome by the deployment of high-temperature gasification process technology, where relatively high temperature conditions in excess of $750^{\circ} \mathrm{C}[1,2]$ are used by heating the feed gas resulting in the rapid devolatilization of biomass material which enhances the volatile yields, and hence, improving gasification efficiency. 


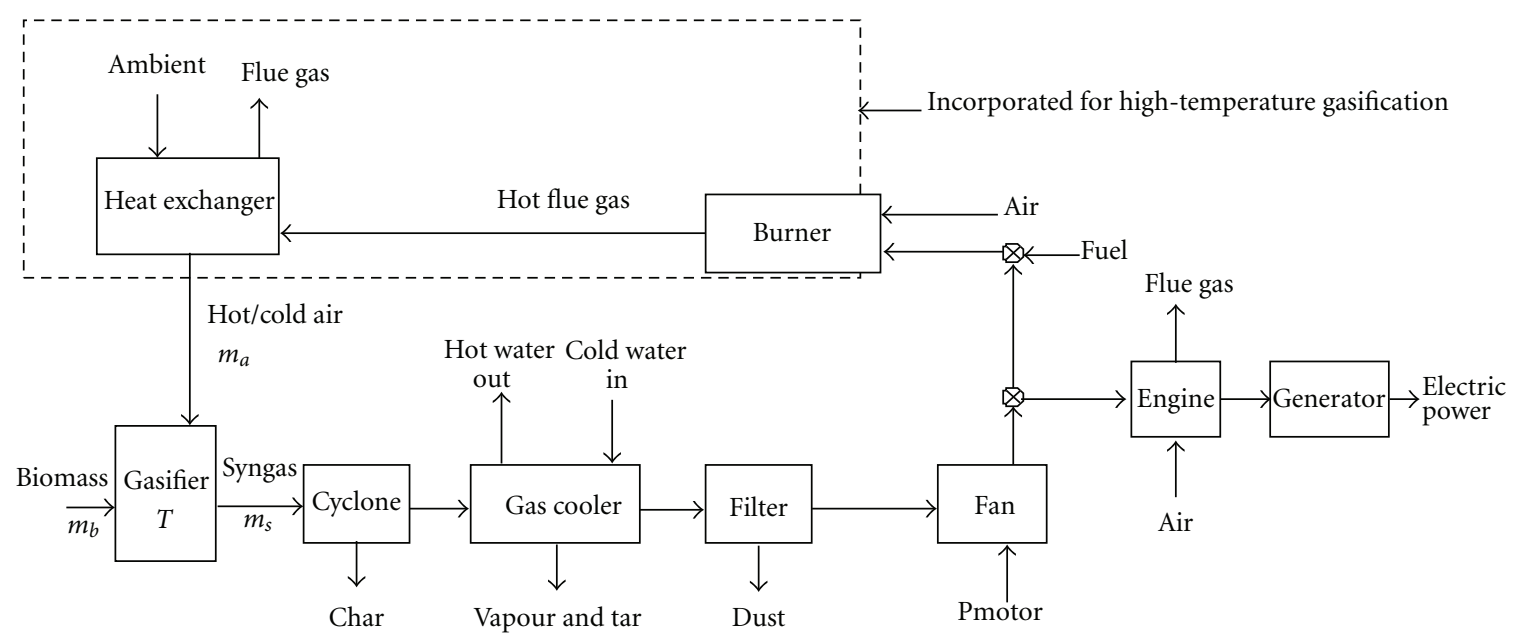

FIGURE 1: Block diagram of the HTAG biomass gasification system.

Maximizing the efficiency of the gasifier can be done through optimization of the operating parameters such as temperature $(T)$ and equivalence ratio (ER). The identification of the inefficiencies and their sources allows effective management and optimization of thermal systems [3]. Poor thermodynamic performance, believed to be the result of exergy losses in thermal processes [4], is investigated by making application of the mathematical modeling technique to establish conditions leading to the production of maximum combustible syngas composition with maximum efficiencies. The described novel approach adopted to analyze the effect of high temperature on the gasification process of biomass is based on the application of the exergy concept.

\section{Process Modeling Approach}

The gasification of biomass results in the production of syngas having a wide range of heating values as a direct result of both the gasifier design used and the reactants chosen. In addition to syngas, other products include char and tars produced at varying degrees. Char chemically consists of devolatilized biomass and has a higher concentration of carbon and a lower concentration of hydrogen than that in biomass. The production of char in gas composition contributes significantly in the reduction of the overall efficiency of the gasification process.

The design study of a downdraft gasifier includes a gas cleaning system (cyclone and filter) and gas engine for power generation as presented in Figure 1. To minimize the formation of char and improve gasification efficiency, the gasifier employs a high-temperature air gasification (HTAG) technique. During the gasification process, highly preheated air is produced by means of an air preheater including a pair of ceramic honeycomb heat storage beds. With this subprocess, hot flue gas and air are allowed to pass through the honeycomb heat storage beds alternatively set at short switching periods of about 45 seconds. In this way, highly preheated air is generated for use as the biomass gasification agent.

As the syngas exits the gasifier at higher temperature in the range of $1200^{\circ} \mathrm{C}$, before use, the syngas is passed through a gas cleaning system comprising cyclones and filters. Here the clean syngas is also cooled further to about $25^{\circ} \mathrm{C}$, being ready for combustion in a furnace, gas engine, or turbine depending on the desired thermal energy or for electricity production.

\section{Process Model Development}

3.1. The Assumptions. During gasification, as air is passed through the fuel bed, relatively discrete drying, pyrolysis, gasification, and oxidation (combustion) zones develop within the reactor. The fuel is dried and moisture removed in the drying zone. In the pyrolysis zone, fuel is converted to volatile compounds and char. The char is gasified in the presence of reactive agents such as carbon dioxide, steam, hydrogen, and oxygen in the gasification zone. Secondary reactions of primary gases and tars take place in the oxidation zone. Because the major product of biomass at temperatures below $600^{\circ} \mathrm{C}$ is char, biomass gasification requires high temperatures in order to gasify char. The location of these zones within a reactor depends on the relative movement of fuel and air, and the zones are differentiated by the variety of reactions and their temperatures. The depth and relative importance of each zone depend on the chemical composition of the fuel, its moisture content and particle size, the mass flow rate of the reactive agent, and the bed temperature.

The important chemical reactions that occur in the gasifier during biomass gasification are based on the following assumptions:

(i) biomass is represented by the general formula $\mathrm{CH}_{x} \mathrm{O}_{y}$,

(ii) the reactions in the gasifier are at thermodynamic equilibrium (at atmospheric pressure $=1 \mathrm{bar}$ ),

(iii) the reactions proceed adiabatically (heat losses neglected),

(iv) ashes are considered to be negligible (very small amount $1 \%$ ), 


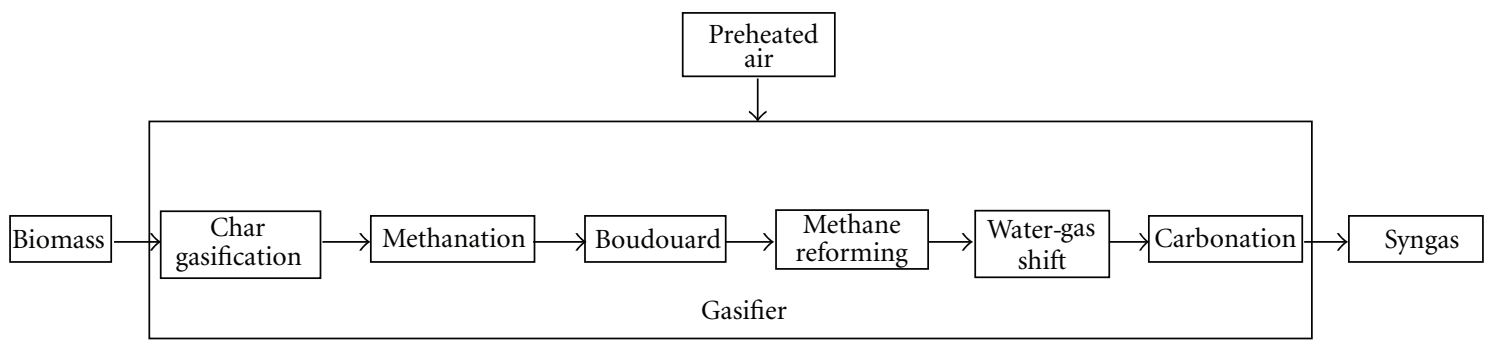

FIGURE 2: Block diagram for modeling HTAG gasification process in the gasifier.

(v) the reactions of heat losses are neglected (Adiabatic process),

(vi) no chars living with the exit of the gasifier products.

To model the gasification process, chemical reactions that occur in the gasifier are considered to be divided into several subprocesses that are represented by a block diagram shown in Figure 2.

The important reactions that occur during biomass conversion based on the above assumptions can be described using the global gasification equation, in which the amount of air to be used in the gasification process $\left(m_{1}\right)$ is determined from

$$
\begin{aligned}
\mathrm{CH}_{x} \mathrm{O}_{y} \mathrm{~N}_{z} & +w \mathrm{H}_{2} \mathrm{O}+m_{1}\left(\mathrm{O}_{2}+3.76 \mathrm{~N}_{2}\right) \longrightarrow n_{\mathrm{H}_{2}} \mathrm{H}_{2} \\
& +n_{\mathrm{CO}} \mathrm{CO}+n_{\mathrm{CO}_{2}} \mathrm{CO}_{2}+n_{\mathrm{H}_{2} \mathrm{O}} \mathrm{H}_{2} \mathrm{O}+n_{\mathrm{CH}_{4}} \mathrm{CH}_{4} \\
& +\left(\frac{z}{2}+3.76 \mathrm{~m}\right) \mathrm{N}_{2}
\end{aligned}
$$

where $x, y$, and $z$ are the number of atoms of hydrogen, oxygen, and nitrogen per the number of atoms of carbon in the feedstock, respectively, $n_{\mathrm{CO}}, n_{\mathrm{CO}_{2}}, n_{\mathrm{H}_{2}}, n_{\mathrm{H}_{2} \mathrm{O}}$, and $n_{\mathrm{CH}_{4}}$ are the numbers of moles of carbon monoxide, carbon dioxide, hydrogen, moisture and methane, obtained by determining chemical composition of feedstock material using a proximate and ultimate analysis, and $w$ is the amount of moisture per kmol of feedstock.

The values on the left-hand side of (1) are obtained from proximate and ultimate analysis and are defined at $25^{\circ} \mathrm{C}$ and 1 bar. On the right-hand side, the $n_{i}$ numbers of mole, of the species $i$ are also unknown; it is possible to establish the coefficients of the product gas components.

Similarly, the amount of air $\left(m_{2}\right)$ required under stochiometric condition made use of the following equation:

$$
\begin{aligned}
\mathrm{CH}_{x} \mathrm{O}_{y} \mathrm{~N}_{z} & +w \mathrm{H}_{2} \mathrm{O}+m_{2}\left(\mathrm{O}_{2}+3.76 \mathrm{~N}_{2}\right) \longrightarrow I \mathrm{CO}_{2} \\
& +J \mathrm{H}_{2} \mathrm{O}+K \mathrm{NO}_{2}+3.76 m_{1} \mathrm{~N}_{2}
\end{aligned}
$$

where $I$ is the mole balance for carbon, $J$ is the mole balance for hydrogen, and $K$ is the mole balance nitrogen. The specific chemical reaction equations that take place for during the gasification process are presented in Table 1 .

Out of these, only four reactions are independent reactions, which are the oxidation $\left(R_{1}\right)$, Boudouard reaction $\left(R_{2}\right)$, water gas reaction $\left(R_{3}\right)$, and the methanation reaction $\left(R_{4}\right)$. The water-gas shift reaction can be considered as
TABLE 1: Major chemical gasification reactions.

\begin{tabular}{lcl}
\hline $\begin{array}{l}\text { Reaction } \\
\text { no. }\end{array}$ & Reaction scheme & Chemical reaction \\
\hline$R_{1}(\mathrm{a})$ & $\mathrm{C}+\mathrm{O}_{2} \rightarrow \mathrm{CO}_{2}$ & \\
$R_{1}(\mathrm{~b})$ & $\mathrm{C}+\frac{1}{2} \mathrm{O}_{2} \rightarrow \mathrm{CO}$ & Oxidation reactions \\
& $\mathrm{CO}+\frac{1}{2} \mathrm{O}_{2} \rightarrow \mathrm{CO}_{2}$ & \\
$R_{1}(\mathrm{c})$ & $\mathrm{C}+\mathrm{CO}_{2} \leftrightarrow 2 \mathrm{CO}$ & Boudouard reaction \\
$R_{2}$ & $\mathrm{C}+\mathrm{H}_{2} \mathrm{O} \leftrightarrow \mathrm{CO}+\mathrm{H}_{2}$ & Water-gas reaction \\
$R_{3}$ & $\mathrm{C}+2 \mathrm{H}_{2} \leftrightarrow \mathrm{CH}_{4}$ & Methanation reaction \\
$R_{4}$ & $\mathrm{CO}+\mathrm{H}_{2} \mathrm{O} \leftrightarrow \mathrm{CO}_{2}+\mathrm{H}_{2}$ & Water-gas shift reaction \\
$R_{5}$ & $\mathrm{CH}+\mathrm{H}_{2} \mathrm{O} \leftrightarrow \mathrm{H}_{2}+\mathrm{CO}$ & Methane reforming reaction \\
$R_{6}$ & &
\end{tabular}

the subtraction of the steam gasification and Boudouard reactions. Oxidation reaction is typically assumed to be very fast and goes to completion.

3.2. The Model Equations. In formulating the mathematical model describing the gasification process by performing mass balance in (1), consideration is made with regard to the equivalence ratio (ER), which has the strongest influence on the performance of the gasifier, the effect of the fuel bed temperature on syngas quality, and the thermal efficiency of the reactions. The equivalence ratio (ER) represents the ratio between the amount of air $\left(m_{1}\right)$ to be used for the gasification process and the stoichiometric amount of air $\left(m_{2}\right)$. The recommended ER values for the ideal gasification process are in the range between 0.19 and 0.43 [2].

By applying the first law of thermodynamics, the equations that take into account of mole balance on carbon, hydrogen and oxygen, related with the number of atoms in the reactants and the product gas emanating from the global gasification reaction equation (1), are

carbon balance:

$$
f_{1}=0=n_{\mathrm{CO}}+n_{\mathrm{CO}_{2}}+n_{\mathrm{CH}_{4}}-1,
$$

hydrogen balance:

$$
f_{2}=0=2 n_{\mathrm{H}_{2}}+2 n_{\mathrm{H}_{2} \mathrm{O}}+4 n_{\mathrm{CH}_{4}}-x-2 w,
$$

oxygen balance:

$$
f_{3}=0=n_{\mathrm{CO}}+n_{\mathrm{CO}_{2}}+n_{\mathrm{H}_{2} \mathrm{O}}-w-2 m-y,
$$

where $f_{1}, f_{2}$ and $f_{3}$, are functions resulting from the balancing of the number of moles from the global gasification reaction. 
TABLE 2: The value of $\bar{h}_{f}^{O}(\mathrm{~kJ} / \mathrm{mol})$ and coefficients of the empirical equation for $\Delta \bar{g}_{f, T}^{O}(\mathrm{~kJ} / \mathrm{mol})$.

\begin{tabular}{|c|c|c|c|c|c|c|c|c|}
\hline Compound & $\bar{h}_{f}^{O}$ & $a^{\prime}$ & $b^{\prime}$ & $c^{\prime}$ & $d^{\prime}$ & $e^{\prime}$ & $f^{\prime}$ & $g^{\prime}$ \\
\hline $\mathrm{CO}$ & -110.5 & $5.619 \times 10^{-3}$ & $-1.90 \times 10^{-5}$ & $6.383 \times 10^{-9}$ & $-1.846 \times 10^{-12}$ & $-4.891 \times 10^{2}$ & $8.684 \times 10^{-1}$ & $-6.131 \times 10^{-2}$ \\
\hline $\mathrm{CO}_{2}$ & -393.5 & $-1.949 \times 10^{-2}$ & $3.122 \times 10^{-5}$ & $-2.448 \times 10^{-8}$ & $6.946 \times 10^{-12}$ & $-4.891 \times 10^{2}$ & 5.270 & $-1.207 \times 10^{-1}$ \\
\hline $\mathrm{H}_{2} \mathrm{O}$ & -241.8 & $-8.950 \times 10^{-3}$ & $-3.672 \times 10^{-6}$ & $5.209 \times 10^{-9}$ & $-1.478 \times 10^{-12}$ & 0.0 & 2.868 & $-1.722 \times 10^{-2}$ \\
\hline $\mathrm{CH}_{4}$ & -74.8 & $-4.620 \times 10^{-2}$ & $1.130 \times 10^{-5}$ & $1.319 \times 10^{-8}$ & $-6.647 \times 10^{-12}$ & $-4.891 \times 10^{2}$ & $1.411 \times 10^{1}$ & $-2.234 \times 10^{-1}$ \\
\hline
\end{tabular}

TABLE 3: Characteristic values of selected tropical biomass materials.

\begin{tabular}{lccccccccc}
\hline \multirow{2}{*}{ Biomass type } & \multicolumn{4}{c}{ Ultimate analysis (\%), dry basis } & \multicolumn{3}{c}{ Proximate analysis (\%), dry basis } & \multicolumn{2}{c}{ High heating value } \\
& $\mathrm{C}$ & $\mathrm{H}$ & $\mathrm{O}$ & $\mathrm{N}$ & Moisture & Volatile matter & Fixed carbon & Ash & HHV (kJ/kg) \\
\hline (1) Palm stem & 47.50 & 5.90 & 42.50 & 0.28 & 9.10 & 81.20 & 15.30 & 3.50 & 17,380 \\
(2) Rice husks & 35.60 & 4.50 & 33.40 & 0.19 & 8.80 & 59.20 & 14.60 & 26.20 & 13,240 \\
(3) Sugarcane bagasse & 48.10 & 5.90 & 42.40 & 0.15 & 9.00 & 80.50 & 16.20 & 3.30 & 17,330 \\
\hline
\end{tabular}

In the elemental balancing equations (3), (4), and (5), there are 5 unknowns, $n_{\mathrm{CO}}, n_{\mathrm{CO}_{2}}, n_{\mathrm{H}_{2}}, n_{\mathrm{H}_{2} \mathrm{O}}$, and $n_{\mathrm{CH}_{4}}$. To obtain a complete solution, two more equations are needed. These equations are derived from the equilibrium constant of the reaction occurring in the gasification zone, the reaction kinetics, and thermal balance, based on the methanation $R_{4}$ and water-gas shift reaction $R_{5}$, as expressed in the form

$$
\begin{aligned}
& K_{1}=\prod_{i}\left(x_{i}\right)^{v i}\left(\frac{P}{P^{o}}\right)^{\sum_{i} v i}=\frac{\left(n_{\mathrm{CH}_{4}}\right)\left(n_{\text {total }}\right)}{\left(n_{\mathrm{H}_{2}}\right)^{2}}, \\
& K_{2}=\prod_{i}\left(x_{i}\right)^{v i}\left(\frac{P}{P^{o}}\right)^{\sum_{i} v i}=\frac{\left(n_{\mathrm{CO}_{2}}\right)\left(n_{\mathrm{H}_{2}}\right)}{\left(n_{\mathrm{CO}}\right)\left(n_{\mathrm{H}_{2} \mathrm{O}}\right)},
\end{aligned}
$$

where $x_{i}$ is the mole fraction of species $i$ in the ideal gas mixture, $v$ is the stoichiometric number, $P^{o}$ is the standard pressure, 1 atom, $n_{\text {total }}$ is the total mole of producer gas, $K_{1}$ and $K_{2}$ are the equilibrium constants of methanation and water-gas shift reactions, respectively, resulting from the ratio of products to reactants of these reactions. The obtained equations can be reduced into the following functions:

$$
\begin{aligned}
& f_{4}=0=K_{1}\left(n_{\mathrm{H}_{2}}\right)^{2}-\left(n_{\mathrm{CH}_{4}}\right)\left(n_{\text {total }}\right), \\
& f_{5}=0=K_{2}\left(n_{\mathrm{CO}}\right)\left(n_{\mathrm{H}_{2} \mathrm{O}}\right)-\left(n_{\mathrm{CO}_{2}}\right)\left(n_{\mathrm{H}_{2}}\right) .
\end{aligned}
$$

The resulting equilibrium constants are determined using the expressions

$$
\begin{gathered}
\ln K=-\frac{\Delta G_{T}^{O}}{R_{o} T}, \\
\Delta G_{T}^{O}=\sum_{i} v i \Delta \bar{g}_{f, T, i}^{o},
\end{gathered}
$$

where $R_{o}$ is the universal gas constant $8.314 \mathrm{~kJ} / \mathrm{kmolK}, \Delta G_{T}^{o}$ is the standard Gibbs free energy function of reaction, and $\Delta \bar{g}_{f, T, i}^{O}$ is representing the standard Gibbs function of formation at a given temperature $T$ of the gas species $i$ which can be expressed by the following equation:

$$
\begin{aligned}
\Delta \bar{g}_{f, T}^{O}= & \bar{h}_{f}^{o}-a^{\prime} T \ln (T)-b^{\prime} T^{2}-\left(\frac{c^{\prime}}{2}\right) T^{3} \\
& -\left(\frac{d^{\prime}}{3}\right) T^{4}+\left(\frac{e^{\prime}}{2 T}\right)+f^{\prime}+g^{\prime} T,
\end{aligned}
$$

where the values of the coefficients $a^{\prime}, b^{\prime}, c^{\prime}, d^{\prime}, e^{\prime}, f^{\prime}$, and $g^{\prime}$ are determined in accordance with [5], and the corresponding coefficient values for each gas composition are presented in Table 2.

The resulting eight nonlinear algebraic equations (3) through (5), (6), (7), (8), (9), and (12) are solved simultaneously in order to determine the number of moles $n_{\mathrm{CO}}, n_{\mathrm{CO}_{2}}, n_{\mathrm{H}_{2}}, n_{\mathrm{H}_{2} \mathrm{O}}$, and $n_{\mathrm{CH}_{4}}$ (which determine the product gas composition) and temperature at various equivalence ratios (ERs). The equilibrium model is simulated using the mass balance equation (1).

The proximate and ultimate analyses of the three types of biomass materials used in this study as initial inputs to the model are presented in Table 3 .

3.3. Exergy Efficiencies. Biomass gasification is associated with the energy interchange processes during which the chemical energy of the biomass is converted into the chemical and thermal energy of the product gas (syngas). The energetic biomass conversion efficiency is dependent on the gasifier, whose performance is evaluated using the second law of thermodynamics applying the exergy analysis concept to model the energy interchange processes $[6,7]$. The used method has already been applied before for system optimization, and only its main features are presented in this paper.

The total system exergy $(\varepsilon)$ is generally divided into four components, namely, physical exergy, kinetic exergy, potential exergy, and chemical exergy, each having two parts: (i) the thermomechanical contribution and (ii) the chemical contribution. Thermomechanical exergy (or physical exergy), is the maximum amount of work that can be achieved by a state of a substance as it enters into thermal and mechanical equilibrium with the environment. Assuming the kinetic and potential energy contributions to be negligible, only the chemical and physical exergies of species exist, and the gasifier performance is evaluated by determining the lower heating value of syngas $\mathrm{LHV}_{\text {gas }}$, cold efficiency $\eta_{\text {cold }}$, the exergy efficiency $\eta_{\text {ex }}$, and the exergy losses $I$ (irreversibility) after finding the molar composition values of gaseous species in the product gases: $n_{\mathrm{CO}}, n_{\mathrm{CO}_{2}}, n_{\mathrm{H}_{2}}, n_{\mathrm{H}_{2} \mathrm{O}}$, and $n_{\mathrm{CH}_{4}}$. The exergy efficiency in the product gas is calculated per $1 \mathrm{~kg}$ of biomass. 
3.3.1. Exergy Efficiencies. The exergy efficiency of a system can be expressed in terms of chemical exergy $\eta_{\text {ex, chemical }}$ efficiency only. The chemical exergy efficiency of a process is defined as the ratio between the chemical exergies of the product gas and total materials input (for this study they are biomass and heated air):

$$
\eta_{\text {ex, chemical }}=\frac{\varepsilon_{\text {product }}}{\varepsilon_{\text {input }}}=\frac{\varepsilon_{\text {ch, gas }}+\varepsilon_{\text {ph, gas }}}{\varepsilon_{\text {ch,biomass }}+\varepsilon_{\text {ph, med }}},
$$

where $\varepsilon_{\mathrm{ch} \text {, gas }}$ is the chemical exergy of the product gas, $\varepsilon_{\text {ch,biomass }}$ is the chemical exergy of the biomass material, $\varepsilon_{\text {ph, gas }}$ is the physical exergy of the product gas, and $\varepsilon_{\text {ph,med }}$ is the preheated air exergy.

Chemical Exergy of the Gas, $\varepsilon_{\mathrm{ch}, \mathrm{gas}}$. The chemical exergy of the product gas stream of multiple components $\varepsilon_{\text {ch,gas }}$ is modeled using the following expression:

$$
\varepsilon_{\mathrm{ch}, \text { gas }}=\sum_{i} \chi_{i} \varepsilon_{\mathrm{ch}, i}+R_{o} T_{o} \sum_{i} \chi_{i} \ln \chi_{i}
$$

where $\chi_{i}$ and $\varepsilon_{\mathrm{ch}, i}$ are the mole fraction and chemical exergy of individual gas components $i$, respectively, $R_{o}$ is the universal gas constant $(8.314 \mathrm{~kJ} / \mathrm{kmolK})$, and $T_{o}$ is the standard temperature $(298 \mathrm{~K})$. The values of $\chi_{i}$ for each element can be determined by dividing the number of moles for each gas component, $n_{i}\left(\mathrm{H}_{2}, \mathrm{CO}, \mathrm{CO}_{2}, \mathrm{H}_{2} \mathrm{O}, \mathrm{CH}_{4}\right.$ and $\left.\mathrm{N}_{2}\right)$, with the total number of moles of the gas component $\sum n_{i}$ under specified conditions using the following expression:

$$
\chi_{i}=\frac{n_{i}}{\sum n_{i}} .
$$

For the purpose of this study, the corresponding values of the chemical exergy $\varepsilon_{\mathrm{ch}, i}$ for syngas composition component $\left(\mathrm{H}_{2}, \mathrm{CO}, \mathrm{CO}_{2}, \mathrm{H}_{2} \mathrm{O}, \mathrm{CH}_{4}\right.$, and $\left.\mathrm{N}_{2}\right)$ were obtained using the standard values as reported in the study by $[8,9]$ presented in Table 4.

Chemical Exergy of Biomass, $\varepsilon_{\text {ch,biomass. The corresponding }}$ chemical exergy $\varepsilon_{\text {ch,biomass }}$ of the biomass material is also determined using the following expression:

$$
\varepsilon_{\text {ch,biomass }}=\beta \mathrm{LHV}_{\text {biomass }},
$$

where $\mathrm{LHV}_{\text {biomass }}$ is the lower heating (calorific) value of biomass, and $\beta$ is a factor dependent upon mass fraction of oxygen, carbon, hydrogen, and nitrogen in the feedstock [9] and is expressed as

$$
\beta=\frac{1.044+0.0160 Z_{\mathrm{H}}-0.3493 Z_{\mathrm{O}}[\mathcal{R}]+0.0493 Z_{\mathrm{N}}}{1-0.4124 Z_{\mathrm{O}}},
$$

where $[\mathcal{R}]$ denotes $\left[1+0.0531 Z_{\mathrm{H}}\right], Z_{\mathrm{H}}$ is $\mathrm{H} / \mathrm{C}, Z_{\mathrm{O}}$ is $\mathrm{O} / \mathrm{C}, Z_{\mathrm{N}}$ is $\mathrm{N} / \mathrm{C}$ and $\mathrm{H} / \mathrm{C}$, and $\mathrm{O} / \mathrm{C}$ and $\mathrm{N} / \mathrm{C}$ represent atomic ratios of fuel components $\mathrm{H}, \mathrm{C}, \mathrm{O}$, and $\mathrm{N}$ in the solid fuel.

The Physical Exergy of the Gas, $\varepsilon_{\mathrm{ph}, \mathrm{gas}}$. Since the gasification process is designed to occur at higher gasification temperatures, the portion of the physical exergy (sensible heat) is considerable in the total exergy of the product gas. Considering an air-blown adiabatic gasifier, the physical
TABLe 4: Standard chemical exergy of some substances [10].

\begin{tabular}{lc}
\hline Substance & $\varepsilon_{\mathrm{ch}, i}(\mathrm{~kJ} / \mathrm{kmol})$ \\
\hline $\mathrm{H}_{2}$ & 238,490 \\
$\mathrm{CO}$ & 275,430 \\
$\mathrm{CO}_{2}$ & 20,140 \\
$\mathrm{H}_{2} \mathrm{O}(\mathrm{g})$ & 11,710 \\
$\mathrm{CH}_{4}$ & 836,510 \\
$\mathrm{~N}_{2}$ & 720 \\
\hline
\end{tabular}

exergy of the product gas, $\varepsilon_{\text {ph,gas }}$, is determined using the following expression:

$$
\varepsilon_{\mathrm{ph}, \mathrm{gas}}=\left(h_{R}-h_{o}\right)-T_{o}\left(s_{R}-s_{o}\right),
$$

where $h$ and $s$ are the molar specific enthalpy and molar specific entropy, whereas the subscript " $O$ " denotes the original state of the environment, and the subscript $R$ stands for the exit gas enthalpy and entropy states from the gasifier.

Preheated Air Exergy $\varepsilon_{\mathrm{ph} \text {,med }}$. The use of highly preheated air is intended to lead to a faster biomass conversion process, efficient heat transfer, and reduced tar content in the product gas. The determination of the preheated air exergy, $\varepsilon_{\text {ph,med }}$, in the gasifier is obtained from

$$
\varepsilon_{\mathrm{ph}, \text { med }}=\left(h_{H}-h_{o}\right)-T_{o}\left(s_{H}-s_{o}\right),
$$

where $h_{H}$ and $s_{H}$ are the respective enthalpy and entropy of the gas mixture at a given temperature derived from the recuperator, while $h_{o}$ and $s_{o}$ are their respective enthalpy and entropy values of the original state at standard temperature $T_{o}\left(298^{\circ} \mathrm{K}\right)$ and pressure ( 1 bar $)$. The enthalpy $h$ and entropy $s$ values for the medium, air (gas from the recuperator), and gas mixture are temperature dependent, and the values used in this study are based on the work from [11] and the JANAF thermodynamics tables as reported by [12]. The temperature of the hot gas from the recuperator was varied from $800^{\circ} \mathrm{K}$ to $1400^{\circ} \mathrm{K}$.

3.3.2. Cold Exergy Efficiency. To have high system efficiency, it is desirable that the energy that could be converted into work but is wasted (irreversibility, $I$ ) must be as small as possible. The analysis of exergy losses that occur during HTAG process was made using the following equation:

$$
I=\left(1-\eta_{\text {ex,chemical }}\right) \text {, }
$$

where $\eta_{\text {ex,chemical }}$ is the chemical exergy efficiency for the process. The obtained irreversibility is compared with the energy efficiency for HTAG process, generally known as the cold efficiency $\eta_{\text {cold }}$, and is determined using the following equation:

$$
\eta_{\text {cold }}=\frac{\mathrm{LHV}_{\text {gas }}}{\mathrm{LHV}_{\text {biomass }}} .
$$

Both the low heating values for the product gas and biomass were evaluated in this work for each of the syngas components obtained from different types of biomass materials used.

Lower Heating Values of the Biomass ( $\left.\mathrm{LHV}_{\text {biomass }}\right)$. The lower heating values of the biomass ( $\left.\mathrm{LHV}_{\text {biomass }}\right)$ at pressure of 


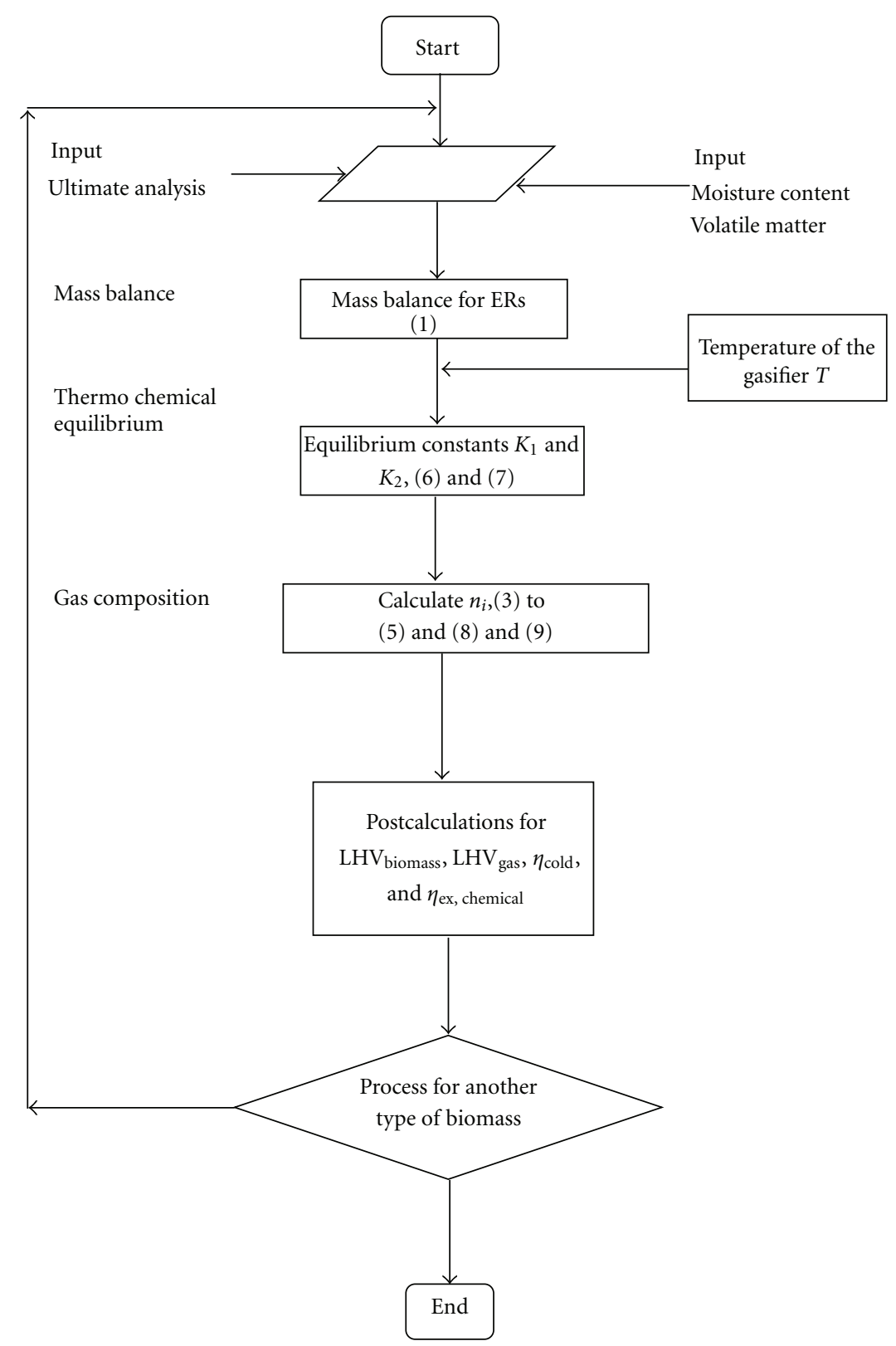

FIGURE 3: Flow chart for the computation of HTAG equilibrium model.

1 bar and temperature condition of $25^{\circ} \mathrm{C}$ are calculated as presented in the following equation:

$$
\mathrm{LHV}_{\text {biomass }}=\mathrm{HHV}-9 m_{\mathrm{H}}\left(h_{f g}\right) \text {, }
$$

where HHV is the higher heating (calorific) value of fuel $(\mathrm{MJ} / \mathrm{kg}), m_{\mathrm{H}}$ is the mass fraction of hydrogen in the solid fuel, and $h_{f g}$ is the enthalpy of vaporization of water. The higher heating values of fuel $(\mathrm{MJ} / \mathrm{kg}$ ) are obtained using the formula expressed as [13]

$$
\begin{aligned}
\mathrm{HHV}= & 0.3491 \mathrm{C}+1.1783 \mathrm{H}+0.1005 \mathrm{~S} \\
& -0.1034 \mathrm{O}-0.0151 \mathrm{~N}-0.0211 \text { Ash, }
\end{aligned}
$$

where $\mathrm{C}, \mathrm{H}, \mathrm{O}, \mathrm{N}, \mathrm{S}$, and Ash are the respective percentages of mass of carbon, hydrogen, oxygen, nitrogen, sulfur, and ash present in the dry solid fuel.
Lower Heating Values of the Gas ( $\left.\mathrm{LHV}_{\text {gas }}\right)$. the lower heating (calorific) value of the product gas $\left(\mathrm{LHV}_{\text {gas }}\right)$ obtained under similar temperature and pressure conditions as for biomass material used is obtained by summing the product of mole fraction $\left(\chi_{i}\right)$ and lower heating values $\mathrm{LHV}_{i}$ and $\mathrm{kJ} / \mathrm{kg}$ of each component in the gas, using the following expression [14]:

$$
\mathrm{LHV}_{\text {gas }}=\sum_{i} \chi_{i} \mathrm{LHV}_{i}
$$

The developed model equations are computed using the MAPLE process simulation code in MATLAB to evaluate the level of the gasifier performance. A flow chart showing the computation steps adopted in the calculation of the system's performance parameters is presented in Figure 3. 
TABLE 5: The effect of preheated air temperature on product gas molar composition.

\begin{tabular}{|c|c|c|c|c|c|c|c|c|c|}
\hline \multirow{3}{*}{ Biomass material } & \multirow{3}{*}{ ER } & \multicolumn{8}{|c|}{ Product gas molar composition (\% Concentration) } \\
\hline & & \multicolumn{2}{|c|}{$\mathrm{H}_{2}$} & \multicolumn{2}{|c|}{$\mathrm{CO}$} & \multicolumn{2}{|c|}{$\mathrm{CH}_{4}$} & \multicolumn{2}{|c|}{$\mathrm{CO}_{2}$} \\
\hline & & $800^{\circ} \mathrm{K}$ & $1400^{\circ} \mathrm{K}$ & $800^{\circ} \mathrm{K}$ & $1400^{\circ} \mathrm{K}$ & $800^{\circ} \mathrm{K}$ & $1400^{\circ} \mathrm{K}$ & $800^{\circ} \mathrm{K}$ & $1400^{\circ} \mathrm{K}$ \\
\hline \multirow{3}{*}{ Rice husks } & 0.3 & 11.5 & 21.3 & 27.3 & 12.5 & 1.2 & 1.3 & 8.9 & 24.1 \\
\hline & 0.35 & 6.8 & 8.7 & 22.4 & 7.5 & 0.7 & 0.3 & 11.6 & 26.8 \\
\hline & 0.4 & 4.2 & 5.02 & 16.5 & 3.9 & 0.26 & 0.1 & 15.7 & 28.4 \\
\hline \multirow{3}{*}{ Sugarcane baggase } & 0.3 & 13.3 & 23.7 & 26.9 & 24.1 & 2.5 & 4.4 & 5.6 & 9.3 \\
\hline & 0.35 & 11.5 & 21.2 & 24.4 & 20.6 & 1.8 & 2.0 & 6.3 & 10.8 \\
\hline & 0.4 & 9.9 & 18.9 & 21.9 & 17.4 & 1.4 & 1.6 & 7.1 & 12.1 \\
\hline \multirow{3}{*}{ Palm stem } & 0.3 & 13.0 & 23.8 & 26.8 & 23.8 & 2.5 & 1.5 & 5.7 & 9.5 \\
\hline & 0.35 & 11.5 & 21.3 & 24.2 & 20.3 & 1.8 & 1.9 & 6.4 & 10.9 \\
\hline & 0.4 & 9.8 & 18.9 & 21.8 & 17.2 & 1.4 & 0.9 & 7.2 & 12.3 \\
\hline
\end{tabular}

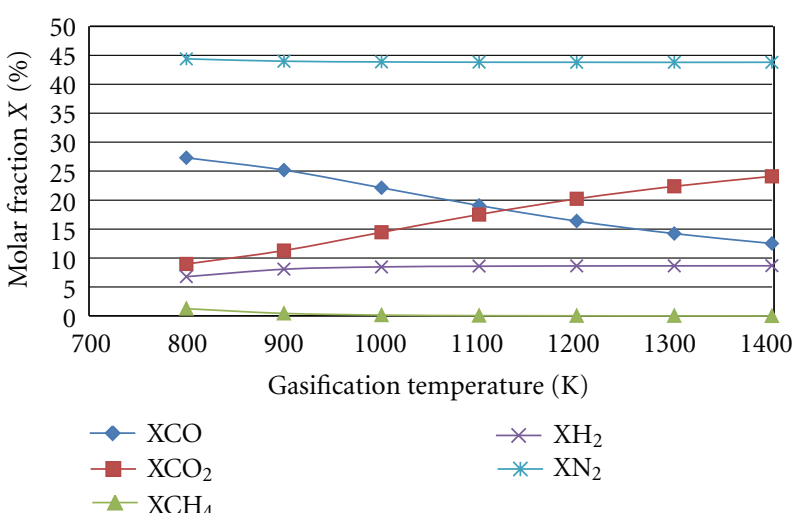

(a)

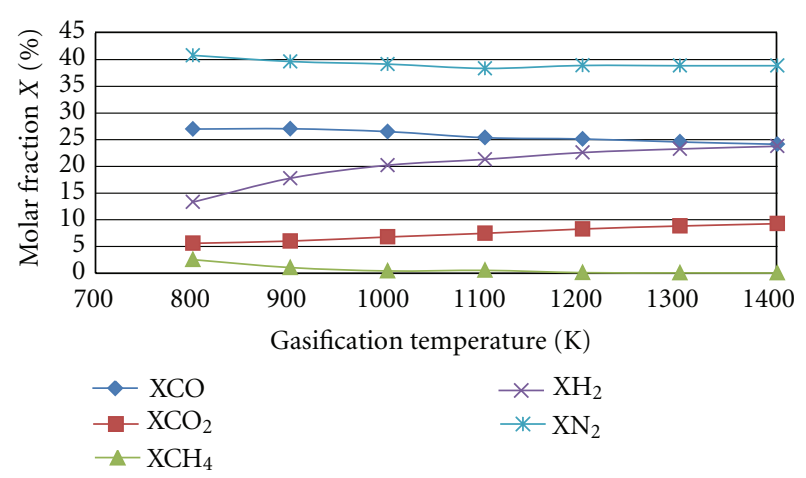

(b)

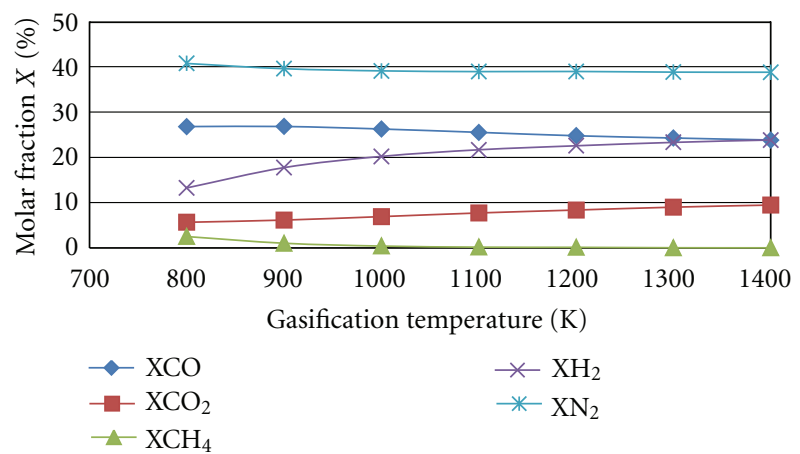

(c)

FIgure 4: The effect of temperature on molar composition for $\mathrm{CO}, \mathrm{CH}_{4}, \mathrm{CO}_{2}$, and $\mathrm{H}_{2}$ gases from the (a) rice husks, (b) sugar bagasse and (c) palm stem (equivalent ratio (ER) of 0.3 ).

\section{Results and Discussions}

4.1. Effects of Preheated Air Temperature on Molar Composition for the Product Gas. The evaluation of the effect of using preheated air on molar composition of the major components of the product gas: carbon monoxide (CO), carbon dioxide $\left(\mathrm{CO}_{2}\right)$, hydrogen $\left(\mathrm{H}_{2}\right)$, and methane $\left(\mathrm{CH}_{4}\right)$ during the gasification of biomass was made using the equilibrium model based on (3) to (5), (8), and (9). The gasification process was conducted under different temperature conditions varying from $800^{\circ} \mathrm{K}$ to $1400^{\circ} \mathrm{K}$ by increasing the temperature at a step size of $100^{\circ} \mathrm{K}$.

For the purpose of this study, three different types of biomass materials were used as the inputs: rice husks, sugar cane baggase, and palm stem. Additionally, the gasification process was done under different equivalent ratio (ER) values of $0.3,0.35$, and 0.4 . The model results obtained showing how the use of preheated air affected the gasification process, and the evolution of product gas molar fraction values for each biomass material used: (a) rice husks, (b) sugar cane bagasse, and (c) palm stem are shown in Figures 4 through 6 .

Analyses of the results shown in Figure 4(a) to Figure 6(a) for rice husks, Figure 4(b) to Figure 6(b) for the case of sugar baggase, and Figure 4(c) to Figure 6(c) for palm stem indicate that as the ER is increased from 0.3 to 0.4 , the molar concentration of the product gas composition of $\mathrm{H}_{2}, \mathrm{CO}$, and $\mathrm{CH}_{4}$ decreases as seen clearly in Table 5. While this is the case 


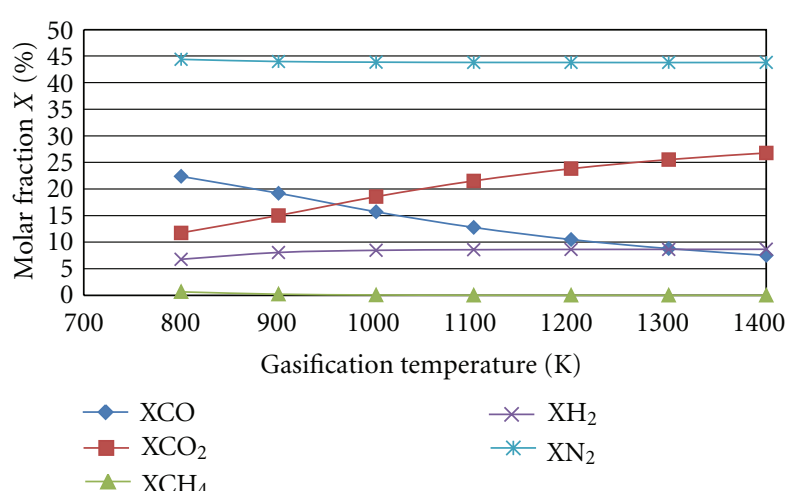

(a)

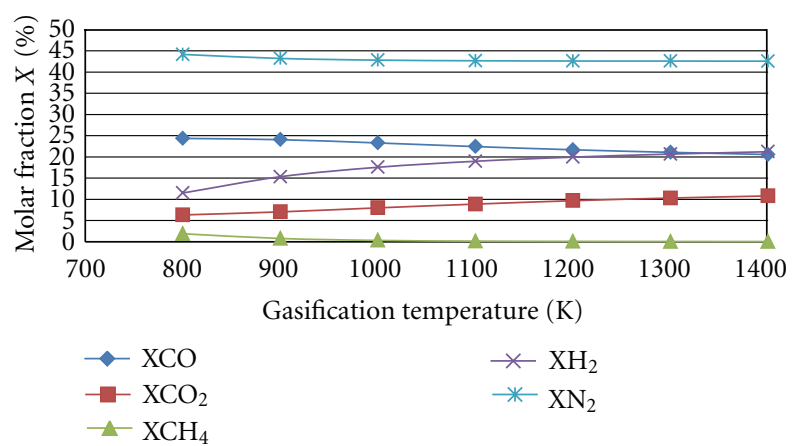

(b)

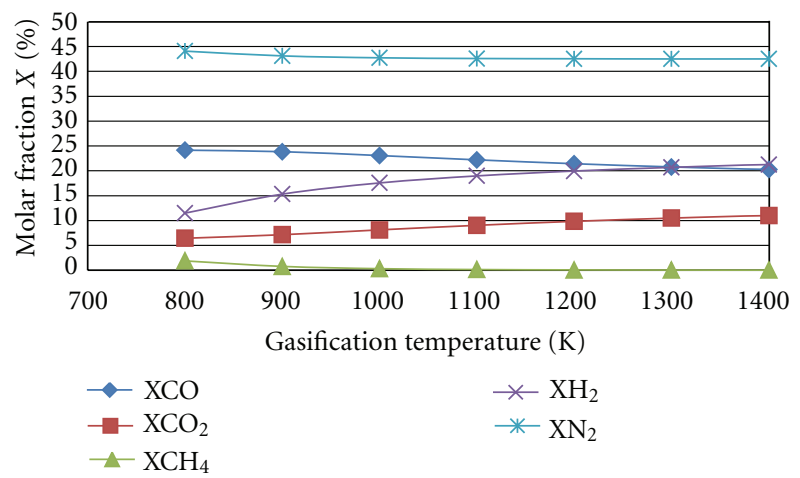

(c)

FIGURE 5: The effect of temperature on molar composition for $\mathrm{CO}, \mathrm{CH}_{4}, \mathrm{CO}_{2}$, and $\mathrm{H}_{2}$ gases from the (a) rice husks, (b) sugar bagasse, and (c) palm stem (equivalent ratio (ER) of 0.35 ).

for these components, the trend is different for $\mathrm{CO}_{2}$ which shows a reverse trend, by which its molar concentration is seen to increase as the ER and temperature are increased.

The application of higher heating rates provided by the preheated air that increased from $800^{\circ} \mathrm{K}$ to $1400^{\circ} \mathrm{K}$, allows the formation of a reasonable amount of $\mathrm{H}_{2}$, but such temperature increases resulted into a decrease in $\mathrm{CO}$ molar concentration. The reduction in CO production observed in this study may have occurred at the comparatively lower temperature at $850-900^{\circ} \mathrm{C}(1123-1173 \mathrm{~K})$ for which the Boudouard reaction predominated the process. Similar results were also reported in the study in [15].

In this study, $\mathrm{CH}_{4}$ molar concentration reduction observed was relatively small depending on the type of biomass material. However, the predictions made for $\mathrm{CH}_{4}$ using the thermodynamics equilibrium model are significantly lower than those encountered in the practical gasification process $[7,16]$. The typical $\mathrm{CH}_{4}$ concentration in most downdraft gasifiers is in the range of $2-5 \%$ [6].

These results indicate that the $\mathrm{CO}_{2}$ molar concentrations increases are higher in rice husks compared to relatively small increases in sugar cane baggase and palm stem biomass types. The molar concentration of $\mathrm{CO}_{2}$ in the two biomass materials was in a relatively same range under the similar temperature conditions and the same ER values.

4.2. Effects of Preheated Air Temperature on Gasifier Exergy Efficiency. For the ability of the gasifier to achieve high system efficiency, it is desirable that the energy that could be converted into work but is wasted (irreversibility, $I$ ) must be as small as possible. The analysis of exergy losses that occur during HTAG process takes into consideration the chemical exergy efficiency $\eta_{\text {ex,chemical }}$ for the process using $(20)$. The obtained irreversibility results compared with the energy efficiency for HTAG process, generally known as the cold efficiency $\eta_{\text {cold }}$ (or first law of thermodynamics efficiency), depend on the low heating values for the product gas and different types of biomass materials which are evaluated in (21).

4.2.1. Lower Heating Values of the Biomass ( $\left.L H V_{\text {biomass }}\right)$. The lower heating values of the biomass ( $\left.\mathrm{LHV}_{\text {biomass }}\right)$ at pressure of 1 bar and temperature condition of $25^{\circ} \mathrm{C}$ are calculated using (22) [13], the mass fraction of hydrogen $m_{\mathrm{H}}$ in the solid fuel, and the enthalpy $h_{f g}$ of vaporization of water obtained from Table 2. The results of lower heating values $(\mathrm{MJ} / \mathrm{kg})$ of the materials used are obtained using the formula expressed as (22).

4.2.2. Lower Heating Values of the Gas $\left(L H V_{g a s}\right)$. The greater concentration of carbon monoxide and hydrogen that was established in these results contributes to the attained higher calorific values. The presence of methane in the gas has a tendency of increasing the calorific value. The increase of temperature for (a) rice husks does not; however, support and increase heating values for syngas obtained, while for (b) 


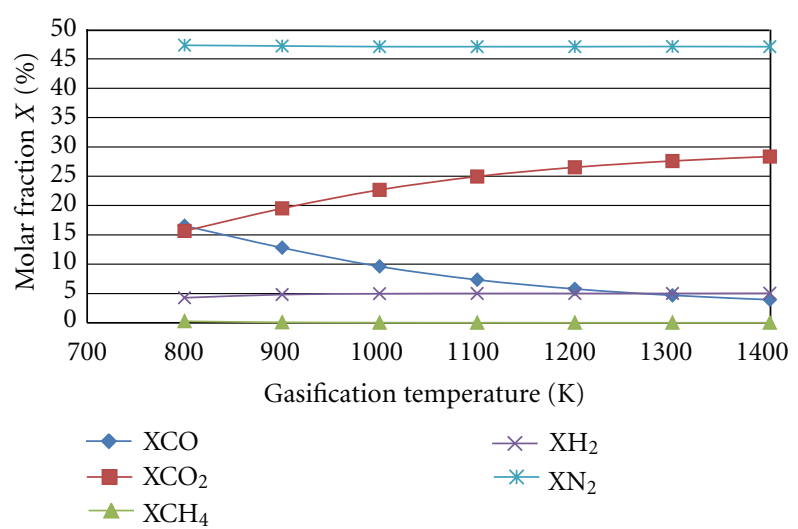

(a)

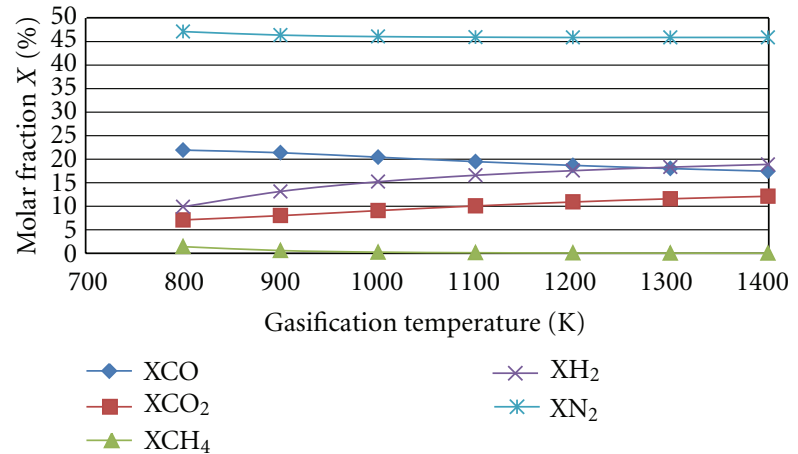

(b)

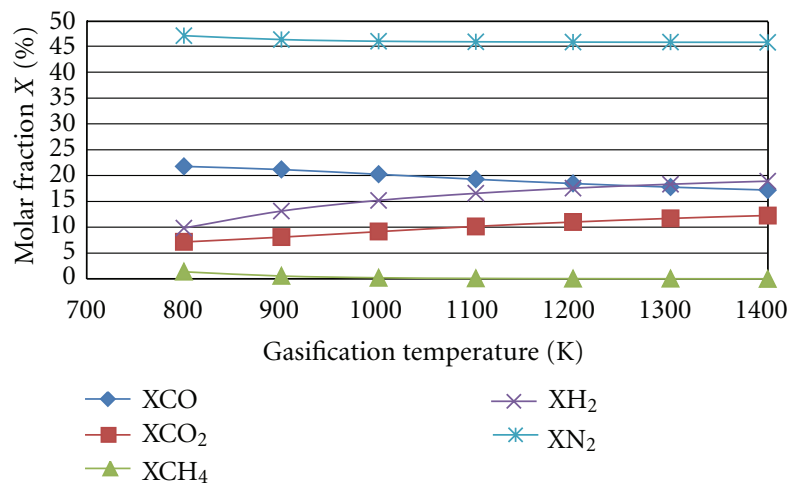

(c)

FIGURE 6: The effect of temperature on molar composition for $\mathrm{CO}, \mathrm{CH}_{4}, \mathrm{CO}_{2}$, and $\mathrm{H}_{2}$ gases from the (a) rice husks, (b) sugar bagasse, and (c) palm stem (equivalent ratio (ER) of 0.4 ).

sugar cane bagasse and (c) palm stem, higher heating values depend more on the ER values.

The lower heating (calorific) value of the product gas $\left(\mathrm{LHV}_{\text {gas }}\right)$ was calculated based on the main composition of the product gas (carbon monoxide and hydrogen) obtained under similar temperature and pressure conditions for all biomass materials used and then by summing the product of mole fraction $\left(\chi_{i}\right)$ of each component in the gas [14]. The results obtained are presented in Table 6 .

These results obtained on the basis of the first law of thermodynamics have a similar efficiency decrease as the ER is increased from 0.3 to 0.4 . The effect of temperature did not show a dramatic increase on the cold gas efficiency (also known as the first law of thermodynamics efficiency). For the types of biomass materials used, the maximum cold efficiency achieved ranges from 39.1 to $69.5 \%$ for rice husks as the gasification temperature increases from $800^{\circ} \mathrm{K}$ to $1400^{\circ} \mathrm{K}$, from 63.1 to $64.7 \%$ for sugarcane baggase, and from $62.964 .6 \%$ for palm stem using ER of 0.3 .

4.2.3. Effects of Preheated Air Temperature on the Second Law Efficiency. The amount of the energy that could be converted into work but is wasted (irreversibility, $I$ ) as exergy losses occur during HTAG process was evaluated by making use of (20), taking into consideration the chemical exergy efficiency $\eta_{\text {ex,chemical }}$ for the process. When preheated air is used in the gasification process, the exergy of the product gas attained depends on the amount of the exergy destroyed (irreversibility $I$ ) in the system. By determining the second law of thermodynamics efficiency, values of the maximum possible amount of the available exergy in the product gas that can be realized by the gasification process of biomass were determined. These results are presented in the form of bar charts in Figures 7(a), 7(b), and 7(c).

Figures $7(a)-7(c)$ show effect of temperature on second law efficiency based on chemical exergy at various equivalence ratios for the three types of biomass materials. The results show that the use of preheated air to achieve high gasification temperatures increase, the second law efficiency based on chemical exergy. These results follow a similar trend when equivalent ratio values are also increased.

Analyses of the results shown in Figure 7(a) for rice husks, Figure 7(b) for the case of sugar baggase, and Figure 7(c) for palm stem are summarized in Table 7(a) which indicates that as the gasification temperature is increased from $800^{\circ} \mathrm{K}$ to $1400^{\circ} \mathrm{K}$, the chemical-based exergy efficiency increases. However, this trend is observed as the ER values are also increased from 0.3 to 0.4 . On the basis of these results, the irreversibility values $(I)$ were observed to decrease as both the temperature and ER values are increased. For all biomass materials used in this study, the irreversibility values $(I)$ were less than 27\%. A summary of these results is given in Table 7 . 
TABLE 6: The effects of preheated air temperature on lower heating value $\left(\mathrm{LHV}_{\text {gas }}\right)$ and cold gas efficiency $\eta_{\text {cold }}(\%)$.

\begin{tabular}{|c|c|c|c|c|c|c|c|}
\hline \multirow{3}{*}{\multicolumn{2}{|c|}{ Biomass material }} & \multicolumn{6}{|c|}{ Product gas heating values $(\mathrm{kJ} / \mathrm{kg})$ and cold gas efficiency $\eta_{\text {cold }}(\%)$} \\
\hline & & \multicolumn{2}{|c|}{ Rice husks } & \multicolumn{2}{|c|}{ Sugarcane baggase } & \multicolumn{2}{|c|}{ Palm stem } \\
\hline & & $800^{\circ} \mathrm{K}$ & $1400^{\circ} \mathrm{K}$ & $800^{\circ} \mathrm{K}$ & $1400^{\circ} \mathrm{K}$ & $800^{\circ} \mathrm{K}$ & $1400^{\circ} \mathrm{K}$ \\
\hline \multirow{3}{*}{ ER } & 0.3 & 4278 & 2402 & 5343 & 5482 & 5309 & 5446 \\
\hline & 0.35 & 3185 & 1466 & 4535 & 4606 & 4505 & 4574 \\
\hline & 0.4 & 2129 & 782 & 3857 & 3876 & 3833 & 3850 \\
\hline \multirow{3}{*}{$\eta_{\text {cold }}(\%)$} & 0.3 & 39.1 & 69.5 & 63.1 & 64.7 & 62.9 & 64.6 \\
\hline & 0.35 & 28.2 & 56.8 & 58.8 & 59.7 & 58.7 & 59.5 \\
\hline & 0.4 & 15.2 & 41.4 & 54.5 & 54.8 & 54.3 & 54.0 \\
\hline
\end{tabular}

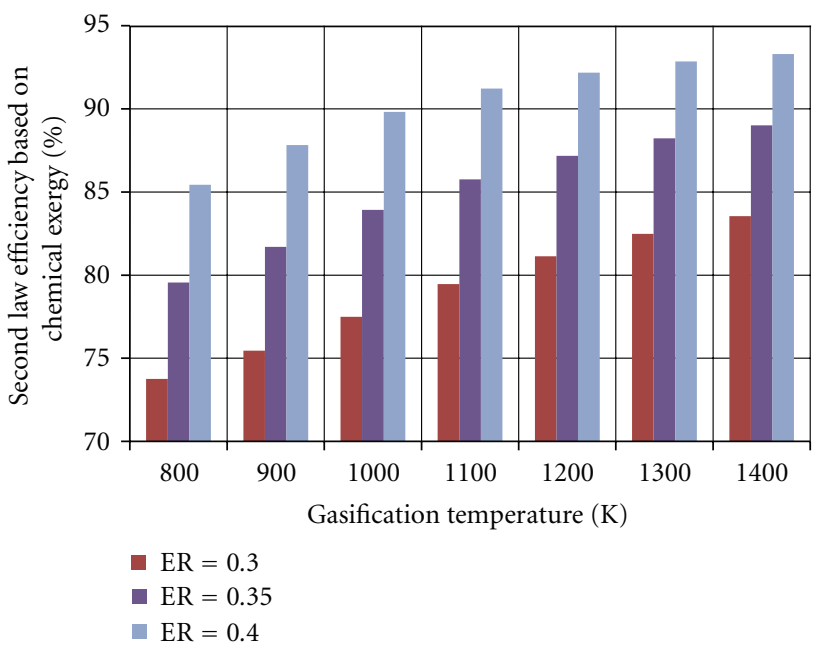

(a)

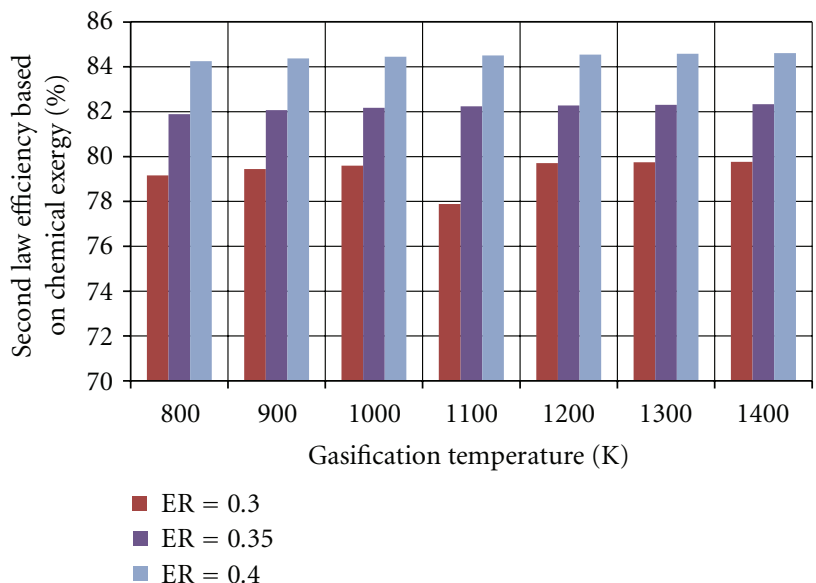

(b)

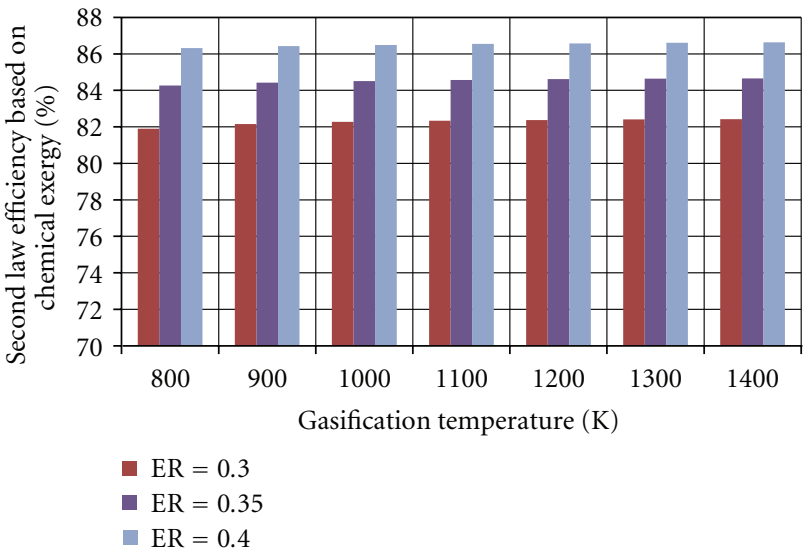

(c)

Figure 7: The effect of temperature and equivalence ratios on second law efficiency based on chemical exergy for (a) Rice husks, (b) Sugar bagasse, and (c) Palm stem.

For the case of combined chemical and physical exergy efficiencies, these results are presented in bar charts provided in Figures $8(\mathrm{a}), 8(\mathrm{~b})$, and $8(\mathrm{c})$.

Examination of the results shown in Figure 8(a) for rice husks, Figure $8(\mathrm{~b})$ for the case of sugar baggase, and Figure $8(\mathrm{c})$ for palm stem shows that increasing the gasifier temperature has an overall negative effect on the exergetic efficiency based on chemical and physical exergy because major chemical exergy carrier components, that is, combustibles in the product gas, are minimized; hence, some of the exergy present in the form of physical exergy is used to heat the reactants. This represents major exergy losses (irreversibility) which have to be minimized by altering the ratio of physical and chemical exergy. 
TABLE 7: The effects of preheated air temperature on (a) chemical, (b) chemical, and physical exergy efficiencies.

(a)

\begin{tabular}{|c|c|c|c|c|c|}
\hline \multirow{3}{*}{$\begin{array}{l}\text { Biomass } \\
\text { material }\end{array}$} & \multirow[t]{3}{*}{ ER } & \multicolumn{4}{|c|}{$\begin{array}{l}\text { Chemical exergy efficiency }\left(\eta_{\text {ex,ch }}\right) \\
\text { and irreversibility }(I) \text { values } \\
\text { for the biomass materials }\end{array}$} \\
\hline & & \multicolumn{2}{|c|}{$\eta_{\text {ex,ch }}(\%)$} & \multicolumn{2}{|c|}{$I(\%)$} \\
\hline & & $800^{\circ} \mathrm{K}$ & $1400^{\circ} \mathrm{K}$ & $800^{\circ} \mathrm{K}$ & $1400^{\circ} \mathrm{K}$ \\
\hline \multirow{3}{*}{ Rice husks } & 0.3 & 73.8 & 83.5 & 26.2 & 16.5 \\
\hline & 0.35 & 79.6 & 89.0 & 20.4 & 11.0 \\
\hline & 0.4 & 85.4 & 93.2 & 14.6 & 6.8 \\
\hline \multirow{3}{*}{$\begin{array}{l}\text { Sugarcane } \\
\text { baggase }\end{array}$} & 0.3 & 79.2 & 79.8 & 20.8 & 20.2 \\
\hline & 0.35 & 82.3 & 81.9 & 17.1 & 17.7 \\
\hline & 0.4 & 84.3 & 84.6 & 15.7 & 15.3 \\
\hline \multirow{3}{*}{ Palm stem } & 0.3 & 81.9 & 82.4 & 19.1 & 18.6 \\
\hline & 0.35 & 84.2 & 84.6 & 15.8 & 15.4 \\
\hline & 0.4 & 86.3 & 86.6 & 13.7 & 13.4 \\
\hline
\end{tabular}

(b)

\begin{tabular}{|c|c|c|c|c|c|}
\hline \multirow{3}{*}{$\begin{array}{l}\text { Biomass } \\
\text { material }\end{array}$} & \multirow[t]{3}{*}{ ER } & \multicolumn{4}{|c|}{$\begin{array}{l}\text { Chemical and physical exergy efficiency } \\
(\eta)_{\text {ex,ch+phy }} \text { and irreversibility }(I) \text { values for } \\
\text { the biomass materials }\end{array}$} \\
\hline & & \multicolumn{3}{|c|}{$\eta_{\mathrm{ex}, \mathrm{ch}+\mathrm{ph}}(\%)$} & \multirow{2}{*}{$\begin{array}{l}I(\%) \\
900^{\circ} \mathrm{K}\end{array}$} \\
\hline & & $800^{\circ} \mathrm{K}$ & $900^{\circ} \mathrm{K}$ & $1400^{\circ} \mathrm{K}$ & \\
\hline \multirow{3}{*}{ Rice husks } & 0.3 & 62.9 & 64.8 & 46.3 & 25.2 \\
\hline & 0.35 & 68.6 & 70.9 & 51.5 & 29.1 \\
\hline & 0.4 & 74.4 & 76.9 & 55.6 & 23.1 \\
\hline \multirow{3}{*}{$\begin{array}{l}\text { Sugarcane } \\
\text { baggase }\end{array}$} & 0.3 & 71.7 & 72.1 & 54.2 & 27.9 \\
\hline & 0.35 & 74.4 & 74.7 & 56.7 & 25.3 \\
\hline & 0.4 & 76.7 & 77.0 & 58.9 & 23.0 \\
\hline \multirow{3}{*}{ Palm stem } & 0.3 & 75.3 & 75.7 & 59.9 & 24.3 \\
\hline & 0.35 & 77.7 & 77.9 & 62.1 & 22.1 \\
\hline & 0.4 & 79.7 & 79.9 & 64.0 & 21.1 \\
\hline
\end{tabular}

The results of the combined chemical and physical exergy efficiencies were observed to fall as the gasification temperature is increased from $800^{\circ} \mathrm{K}$ to $900^{\circ} \mathrm{K}$ and then start to fall as the temperature is increased to $1400^{\circ} \mathrm{K}$. The same trend was also observed as the ER values were increased from 0.3 to 0.4 . These results suggest that for the combined chemical and physical exergy efficiencies, the optimum efficiency value can only be reachs at a temperature of $900 \mathrm{~K}$, which are the low irreversibility values (degree of irreversibility $(I)$ ) for which the system can reach optimum performance. These results are summarized in Table 7.

\section{Model Validation}

The validity of the formulated equilibrium model has been established by making comparison between the results of gaseous compositions predicted in this study and those available from the literature $[2,6,7]$ obtained under similar conditions. The predicted values obtained using the equilibrium models are presented in Table 8 for comparison with those from similar studies. As can be seen from Table 8, the predicted results are in good agreement with the literature results for the major product gas components $\mathrm{CO}$ and $\mathrm{H}_{2}$. In most cases, these results are seen to be a bit higher. The predicted results for $\mathrm{CO}_{2}$ obtained by the formulated equilibrium model are desirable because they are lower compared with the results obtained in previous studies.

\section{Conclusion}

The utilization of biomass can provide sufficient energy which can be used for electricity generation using internal combustion engines. The gasification process in which biomass is converted into clean and combustible gas can be studied using thermodynamic equilibrium model allowing the predicting of the main product gas compositions $\mathrm{CO}, \mathrm{CO}_{2}, \mathrm{H}_{2}$, and $\mathrm{CH}_{4}$ which is an important step in modeling the gasification process. The model assumes that the principle reactions are at thermodynamic equilibrium. The model equations containing four molar balances $(\mathrm{C}, \mathrm{O}$, $\mathrm{H}$, and $\mathrm{N}$ ) and three equilibrium relations are computed using the MAPLE process simulation code in MATLAB. The three types of biomass materials from Tanzania are used for prediction of equilibrium gas compositions. These three samples are compared with results based on percentage mole concentration values that compare favorably well with results obtained from previous studies.

The results for rice husks sugar, sugarcane bagasse, and palm stem indicate that the concentration of $\mathrm{H}_{2}$ has maximum values of about $21.3 \%$ to $23.8 \%$ with a temperature of $1400^{\circ} \mathrm{K}$ and an equivalence ratio of 0.3 , while the formation of $\mathrm{CO}$ is maximum at values of about $26.8 \%$ to $27.3 \%$ at $800^{\circ} \mathrm{K}$ with the same equivalence ratio. While this is the case for $\mathrm{H}_{2}$ and $\mathrm{CO}$, maximum $\mathrm{CO}_{2}$ concentration is about $12.1 \%$ to $28.4 \%$ captured at a temperature of $1400^{\circ} \mathrm{K}$ with an equivalence ratio of 0.4 .

The cold gas efficiency was established to be dependent on the equivalence ratio (ER), which depicted a decreasing trend as the ER was increased. Such reduction is understood to be due to the diversion of energy availability in unconverted solid carbon as well as decreased quality of gas flow, which in turn is caused by decreasing air introduced in large ERs. The loss of cold gas efficiency is also due to the diluting effect of nitrogen content of the oxidant (using air as a gasifying agent). The maximum syngas heating values that were achieved for the biomass materials used were between 4278 and $5482 \mathrm{~kJ} / \mathrm{kg}$ when the ER value was 0.3 .

The high temperatures and equivalent ratio increase favoured the second law efficiency based on chemical exergy with maximum values for thermodynamic efficiency for the types of biomass materials used being between $84.6 \%$ and 93.2\%. The increase in ER value raises the exergetic efficiency based on chemical and physical exergy. The maximum value for thermodynamic gasification efficiency based on chemical exergy for these biomasses ranges from $79.8 \%$ to $93.2 \%$.

The modeling studies conducted gave results that indicate that the application of preheated air has an effect on the increase of the chemical exergy efficiency of the product gas, hence reducing the level of irreversibility. These results show that the efficiency combined based on physical and chemical 
TABLE 8: Comparison of gaseous composition-predicted values with the literature values.

\begin{tabular}{|c|c|c|c|c|c|c|c|c|c|c|c|}
\hline \multicolumn{3}{|c|}{ Ultimate analysis } & \multirow[t]{2}{*}{$T\left({ }^{\circ} \mathrm{K}\right)$} & \multirow[t]{2}{*}{ ER } & \multicolumn{2}{|c|}{ CO \% mole concentration } & \multicolumn{2}{|c|}{$\mathrm{CO}_{2} \%$ mole concentration } & \multicolumn{2}{|c|}{$\mathrm{H}_{2} \%$ mole concentration } & \multirow{2}{*}{ Reference } \\
\hline $\mathrm{C}$ & $\mathrm{H}$ & $\mathrm{O}$ & & & Predicted & Literature & Predicted & Literature & Predicted & Literature & \\
\hline \multirow{3}{*}{47.3} & \multirow{3}{*}{5.8} & \multirow{3}{*}{45.0} & \multirow{3}{*}{1073} & 0.30 & 27.90 & 23.40 & 6.70 & 13.20 & 20.10 & 12.50 & \multirow{3}{*}[2]{} \\
\hline & & & & 0.35 & 24.20 & 24.90 & 8.20 & 12.50 & 17.50 & 13.00 & \\
\hline & & & & 0.40 & 21.04 & 24.20 & 9.50 & 12.80 & 15.20 & 13.80 & \\
\hline 50.0 & 6.0 & 44.0 & 1073 & 0.40 & 22.03 & 22.50 & 8.70 & 9.20 & 15.70 & 16.80 & {$[10]$} \\
\hline 51.0 & 6.8 & 39.2 & 1073 & 0.40 & 20.20 & 24.50 & 7.90 & 6.50 & 15.90 & 15.00 & {$[11]$} \\
\hline
\end{tabular}

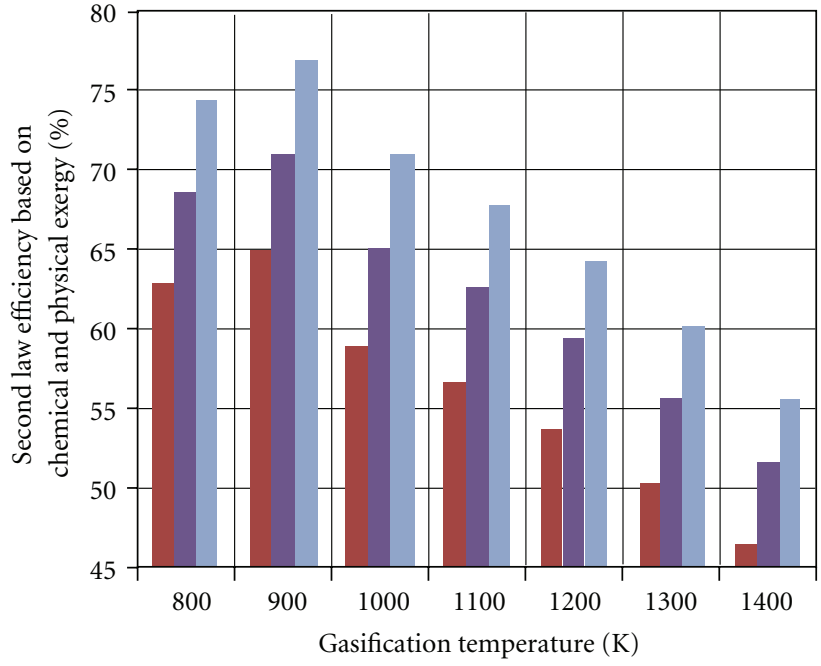

घR $=0.3$

- $\mathrm{ER}=0.35$

$\mathrm{ER}=0.4$

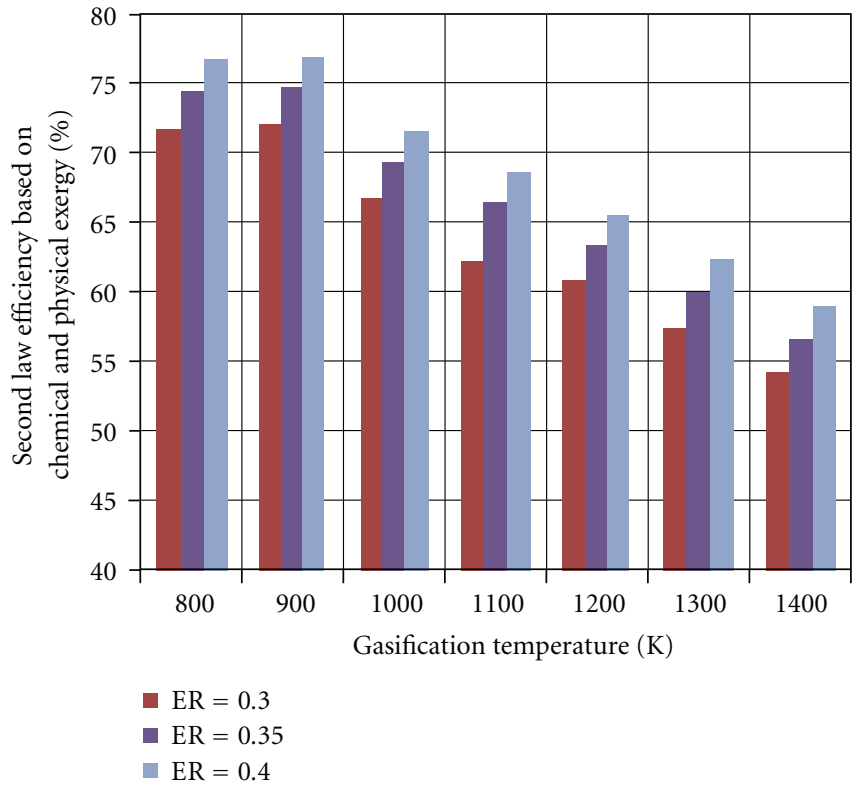

(b)

(a)

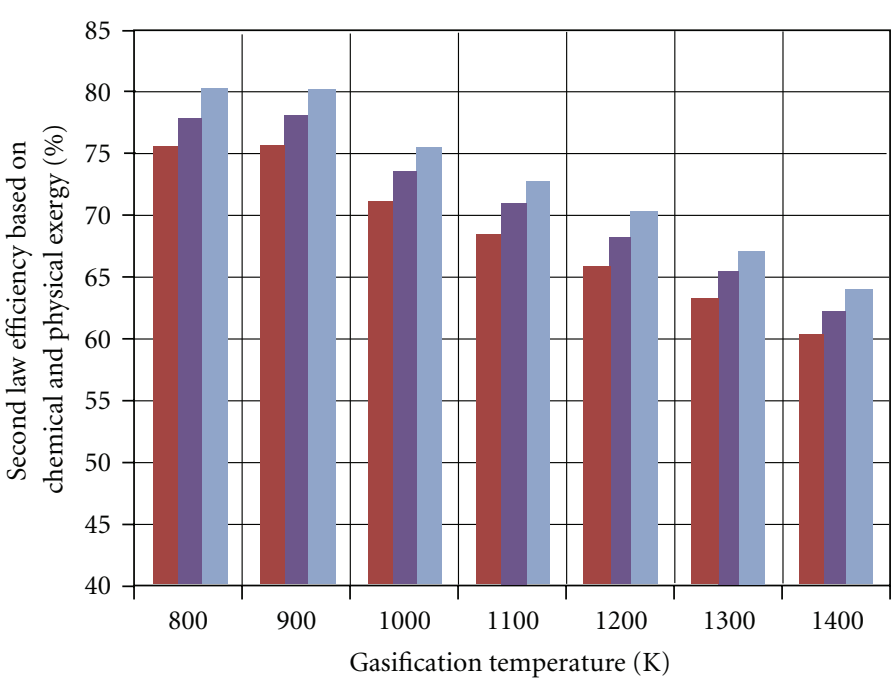

- $\mathrm{ER}=0.3$

- $\mathrm{ER}=0.35$

ER $=0.4$

(c)

FIGURE 8: The effect of temperature and equivalence ratios on second law efficiency based on chemical and physical exergy for (a) rice husks, (b) sugar bagasse, and (c) palm stem. 
exergy is low, which suggests that higher irreversibilities are encountered for this case, as some of the exergy present in form of physical exergy is utilized to heat reactents. Such exergy losses (irreversibilities) can be minimized by altering the ratio of physical and chemical exergy in the syngas production.

\section{References}

[1] C. Lucas, High temperature air/steam gasification of biomass in an updraft fixed bed batch type gasifier [Ph.D. dissertation], Royal Institute of Technology, Stockholm, Sweden, 2005.

[2] Z. A. Zainal, A. Rifau, G. A. Quadir, and K. N. Seetharamu, "Experimental investigation of a downdraft biomass gasifier," Biomass and Bioenergy, vol. 23, no. 4, pp. 283-289, 2002.

[3] H. P. Nuwan, S. De Alwis, A. A. Mohamadand, and A. K. Mehrotra, "Exergy analysis of direct and indirect combustion of methanol by utilizing solar energy or waste heat," Energy and Fuels, vol. 23, no. 3, pp. 1723-1733, 2009.

[4] J. Szargut, "Exergy analysis," The Magazine of Polish Academy of Sciences, vol. 3, no. 7, pp. 31-33, 2005.

[5] A. Sues, M. Juraščík, and K. Ptasinski, "Exergetic evaluation of 5 biowastes-to-biofuels routes via gasification," Energy, vol. 35, no. 2, pp. 996-1007, 2010.

[6] T. Kotas, The Exergy Method of Thermal Plant Analysis, Butterworths, London, UK, 1985.

[7] D. R. Stull and H. Prophet, JANAF Thermochemical Tables, U.S. National Standard Reference Data Series, 37, National Bureau of Standards, 2nd edition, 1971.

[8] R. Strehlow, Combustion Fundamentals, McGraw-Hill, New York, NY, USA, 1985.

[9] K. J. Ptasinski, M. J. Prins, and A. Pierik, "Exergetic evaluation of biomass gasification," Energy, vol. 32, no. 4, pp. 568-574, 2007.

[10] G. Gautam, Parametric study of a commercial-scale biomass downdraft gasifier: experiments and equilibrium modeling [Ph.D. thesis], Graduate Faculty of Auburn University, Auburn, Ala, USA, 2010.

[11] S. Jarungthammachote and A. Dutta, "Thermodynamic equilibrium model and second law analysis of a downdraft waste gasifier," Energy, vol. 32, no. 9, pp. 1660-1669, 2007.

[12] A. Kumar, D. D. Jones, and M. A. Hanna, "Thermochemical biomass gasification: a review of the current status of the technology," Energies, vol. 2, no. 3, pp. 556-581, 2009.

[13] Z. A. Zainal, R. Ali, C. H. Lean, and K. N. Seetharamu, "Prediction of performance of a downdraft gasifier using equilibrium modeling for different biomass materials," Energy Conversion and Management, vol. 42, no. 12, pp. 1499-1515, 2001.

[14] R. Webber, Combustion Fundamentals with Elements of Thermodynamics, Papierflieger, Clausthal-Zellerfeld, Germany, 2008.

[15] A. Kumar, D. Jones, and M. Hanna, "Thermochemical biomass gasification: a review of the current status of the technology," Energies, vol. 2, pp. 556-558, 2009.

[16] S. Parikh, J. Channiwala, and G. Ghosal, "A Correlation for calculating elemental composition from proximate analysis of biomass materials," Journal of Fuel, vol. 86, no. 12-13, pp. 1710-1719, 2007. 

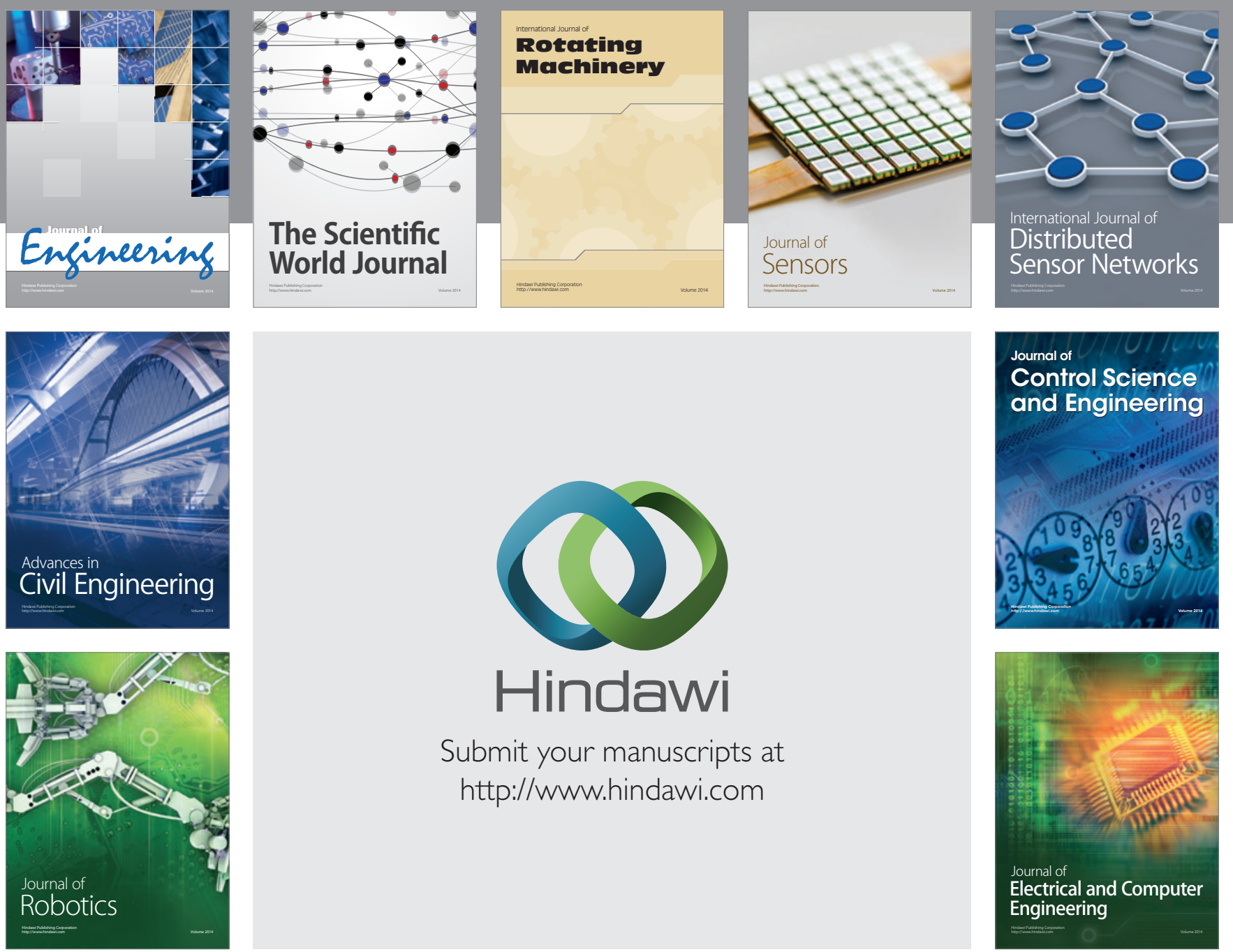

Submit your manuscripts at

http://www.hindawi.com
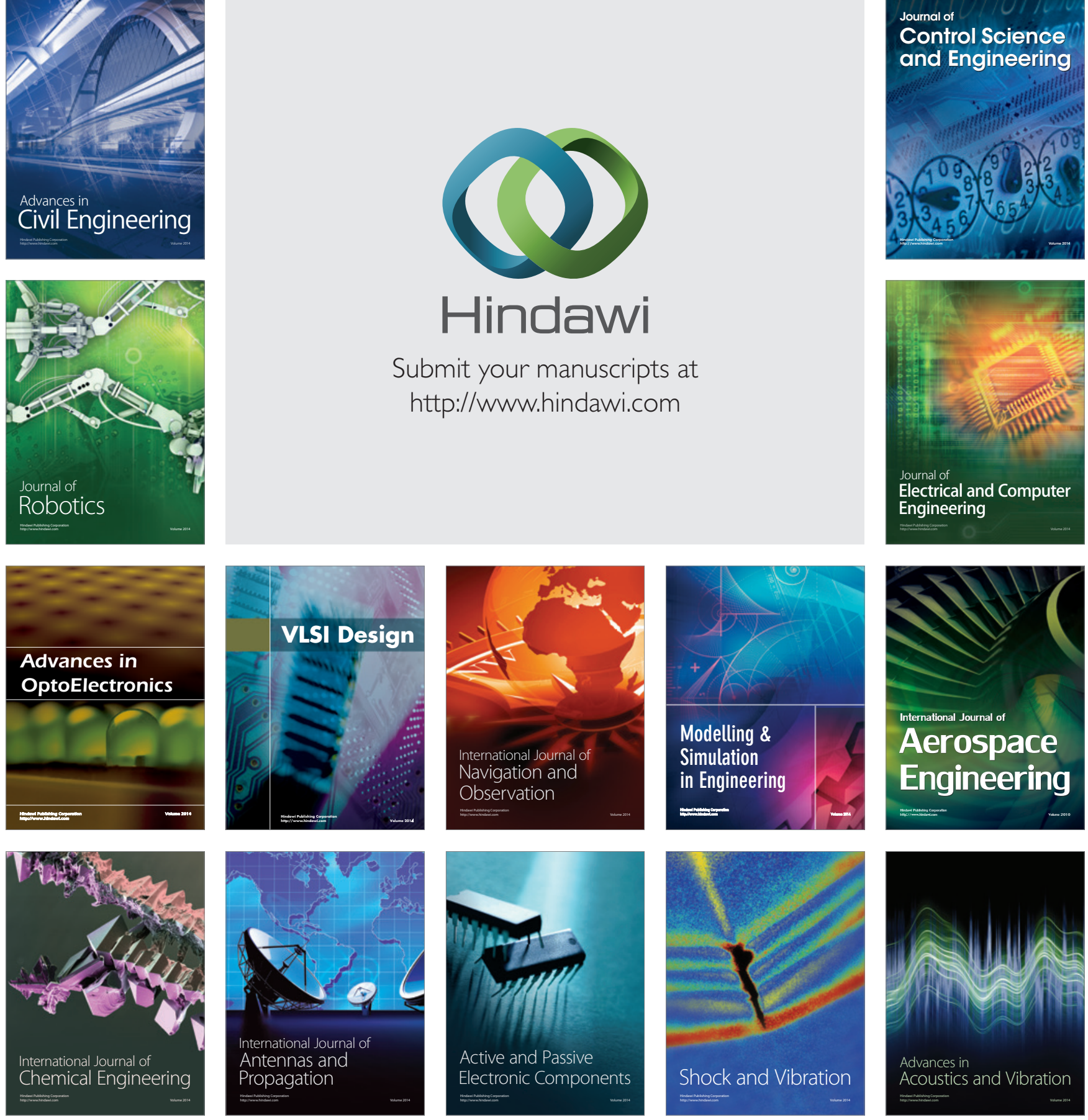